\title{
A modified particle swarm optimization algorithm to enhance MPPT in the PV array
}

\author{
Yoganandini A. P. ${ }^{1}$, Anitha G. S. ${ }^{2}$ \\ ${ }^{1}$ Department of Electronics and Communication, Sambhram Institute of Technology, India \\ ${ }^{2}$ Department of Electrical and Electronics, R. V. College of Engineering (RVCE), India
}

\begin{tabular}{l} 
Article Info \\
Article history: \\
Received Sep 31, 2019 \\
Revised Apr 11, 2020 \\
Accepted Apr 30, 2020 \\
\hline Keywords: \\
Accuracy \\
Efficiency \\
Maximum power point tracking \\
Partial shading \\
Particle swarm optimization \\
Photovoltaic (PV) system \\
Solar radiations \\
Speed
\end{tabular}

\begin{abstract}
Due to the growing demand for electrical power, the researchers are trying to fulfill this demand by considering different ways of renewable energy resource as existing energy resources failed to do so. The solar energy from the sun is freely available, and by using photovoltaic (PV) cell power can be generated. However, it depends on rays fall on the PV cell, climatic condition. Thus, to enhance the efficiency of the photovoltaic (PV) systems, maximum power point tracking (MPPT) of the solar arrays is needed. The output of solar arrays mainly depends on solar irradiance and temperature. The mismatch phenomenon takes place due to partial shade, and it causes to the power output, which brings the incorrect operation of traditional MPP tracker. In this shaded condition, PV array exhibits multiple extreme points. In general, under this scenario, the MPPT approaches fail to judge the MPP, and it leads to low efficiency. The conventional approaches of PSO based algorithms can able to track the MPP under shading condition. However, the optimization process leads to issues in tracking speed. Thus, there a need for an efficient MPPT system which can track MPPT effectively in shaded condition? Hence, the proposed manuscript presents a modified particle swarm optimization (PSO) algorithm is introduced to enhance the tracking speed as well as performance. The outcomes of the proposed system are compared with the traditional PSO system and are found that the tracking speed of MPP, accuracy, and efficiency is improved.
\end{abstract}

Copyright $\odot 2020$ Institute of Advanced Engineering and Science. All rights reserved.

\section{Corresponding Author:}

Yoganandini A. P.,

Department of Electronics and Communication,

Sambhram Institute of Technology,

Bengaluru, India.

Email: yoganandinipari@gmail.com

\section{INTRODUCTION}

The traditional energy resources are not able to fulfill the needs of current power demands. Hence, renewable energy sources like solar, wind, geothermal, and ocean are the better options to fulfill the growing power demand [1, 2]. Among these, the power generation with photovoltaic (PV) cell has gained a lot of power has recently experienced rapid growth around the world [3]. Solar energy has the advantages of the pollution-free energy conversion process and low maintenance cost [4]. However, in the developing process of solar energy, a number of problems are eager to be solved. One of the problems, experts in the whole world, focusing on, is that the efficiency of the optimization process of maximum power point tracking [5]. The recent past has witnessed the different MPPT techniques towards enhancing the performance of dynamic as well as steady-state tracking [6]. One of the tracking technology is found in perturb and observe $(\mathrm{P} \& \mathrm{O})$. But, the partial shading may lead to the mismatch among the components and the aging of the solar panel. In that sense, the traditional techniques are failed to provide optimization at maximum points [7]. In order to overcome this problem, a lot of existing researches were come up with 
significant techniques. Parlak and Can [8] proposed an improved global scanning method which tracks MPPT more accuratelybut consumes a long time in the optimization process leading to power loss. The work of Zhang and Cao [9] has used Fibonacci MPP optimization mechanism which can be adapted for the change in climatic condition, but it also consumes more convergence time. A unique work of Ramaprapha et al. [10] has used the PSO algorithm to select therandom position of particles as an initial value of particles. Also, many other types of research like Shi et al. [11], Gowaid et al. [12], Cheng et al. [13], Sing et al. [14], Yaichi et al. [15], etc. have addressed the issues in MPPT with different approaches. The behavior of the solar WSN under different climatic condition is discussed in Hamili et al. [16]. The work of El malah et al. [17] have discussed a power control mechanisms to reduce the cost and yielding higher performance. In a work of Samosir et al. [18] the fuzzy logic based simulation model is presented to get MPPT for PV application. Thus, in this manuscript, a modified PSO algorithm for MPPT in the PV array is presented to overcome the recent research issue and bring more effectiveness in MPPT. The manuscript is categorized as, section 1 discussing the background of PV circuit, consideration of PSO in MPPT. Section 2 gives research problem, section 3 explains proposed modified PSO algorithm along with algorithm description and implementation, section 4 illustrates the results analysis and section 5 gives the conclusion of the proposed PSO algorithm.

a. The background

From the existing researches of Ishaque et al. [19, 20], Yang et al. [21], Chunhua et al. [22], Dongras et al. [23], found that the PV model with two bypass diodes offers a higher degree of accuracy. The same concept is adapted in designing the PV circuit and has been presented in Figure 1.
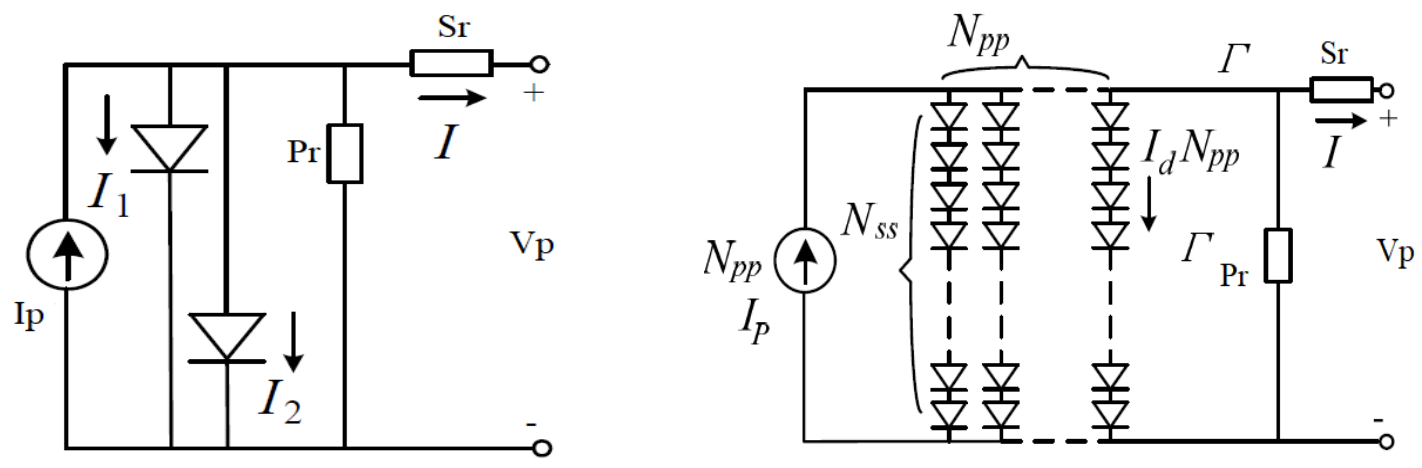

Figure 1. (a) PV circuit, (b) equivalent circuit obtained as

The equivalent model of PV array is given in Figure 1(b), where the output current (I) can be

$$
I=I_{p}-I_{1}\left\{\exp \left(\frac{\left(V+I S_{r}\right)}{\alpha_{1} \times V_{t 1}}\right)-1\right\}-I_{2}\left\{\exp \left(\frac{\left(V+I S_{r}\right)}{\alpha_{2} \times V_{t 2}}\right)-1\right\}-\left(\frac{\left(V+I P_{r}\right)}{P_{r}}\right)
$$

where $I_{p}$ is PV current, $I_{1}$ is current across $\mathrm{D}_{1}, I_{2}$ is current across $\mathrm{D}_{2}$,

$\alpha_{1} \& \alpha_{2} \quad$ : Ideal constant variables of two diodes

$S_{r} \& P_{r} \quad:$ Serial $(<1 \mathrm{~K} \Omega)$ and parallel $(>1 \mathrm{~K} \Omega)$ resistors respectively

$V_{t 1} \& V_{t 2}:$ Thermal voltages having a number of PV cells (Ns)

$$
V_{t 1}=V_{t 2}=\frac{N s \times k T}{q}
$$

where,

$\mathrm{k}:$ Pohl Seidman constant $\left(1.381 \times 10^{-23} \mathrm{~J} / \mathrm{k}\right)$

$\mathrm{q}:$ Charge constant $\left(1.602 \times 10^{-19} \mathrm{C}\right)$

$\mathrm{T}$ : Absolute temperature of PV cell. 
The simplified form of the PV module is given in Figure 1(b), and the output current can be taken as,

$$
I=I_{p}-I_{1}\left\{\exp \left(\frac{\left(V+I S_{r}\right)}{V_{t}}\right)+\right\}-\left\{\exp \left(\frac{\left(V+I P_{r}\right)}{(p-1) \times V_{t}}\right)+2\right\}-\left(\frac{\left(V+I S_{r}\right)}{P_{r}}\right)
$$

For large PV based power generation system, the design of $\mathrm{PV}$ is preferred in Figure 1(b). It contains the series of PV modules (Nss) or parallel of PV modules (Npp). The matrix form of PV design can be represented as, $\left[N_{s s} \times N_{p p}\right]$. Further, to enhance the structure of a series/parallel circuit, the (2) can be modified as,

$$
I=N_{p p}\left[I_{p}-I_{1}\left\{\exp \left(\frac{\left(V+I S_{r} \tau\right)}{N_{s s} \times V_{t}}\right)\right\}-\left\{\exp \left(\frac{\left(V+I P_{r} \tau\right)}{(p-1) \times V_{t} \times N_{s s}}\right)\right\}\right]-\left(\frac{\left(V+I S_{r} \tau\right)}{P_{r} \tau}\right)
$$

where, $\tau=\frac{N_{s s}}{N_{p p}}$

\section{b. PSO in MPPT}

The algorithm of Particle Swarm Optimization (PSO) is presented by Kennedy and Eberhart [20]. This is a significant method which can be used for multimodal function optimization and swarm optimization search guide generated from competition and cooperation among the particles in swarm. To illustrate the PSO algorithm for MPPT controller, the solution vector $\left(x_{i}^{k}\right)$ can be defined.

$$
x_{i}^{k}=d_{j}=\left[d_{1}, d_{2}, d_{3}, \ldots, d_{j}\right]
$$

where, $d_{j}$ is particle duty ratio $=1,2,3 \ldots N_{p}$

The objective function for this duty ratio can be calculated as,

$$
P\left(d_{i}\right)^{k}>P\left(d_{i}\right)^{k-1}
$$

The property of PSO is that it adds three duty cycles $d_{1}, d_{2}, d_{3}$ and forwards then to the power converters to initialize the optimization process. The following Figure 2 gives the movement of particles in search of MPP at different iterations. The triangles represent the duty cycles. In the first iteration as shown in Figure 2(a) of the particle movement, the duty cycles are personal best $\left(P_{b}\right)$ while $d 2$ is global best $\left(G_{b}\right)$ and is the optimal value of PV array.

The movement of particles in the second iteration as shown in Figure 2(b). In this, because of $\mathrm{G}_{\mathrm{b}}$, which is offering optimal value of power (5), the velocity, $\mathrm{Pb}(\mathrm{di})$ is zero, and the factor $\mathrm{G}_{\mathrm{b}}\left(\mathrm{d}_{2}\right)$ is zero. Hence, the velocity of the $G_{b}$ particle $\left(d_{2}\right)$ is zero, which leads to zero speed and unchanged duty ratio. Thus, in search optimization, the particles do not have any effect. In order to utilize this situation, some disturbance will be added, and it assures the change in optimal value. The movement of particles in the third iteration is presented in Figure 2(c). In first two iterations yield better fitness, speed, and the particle direction is unchanged. Hence, they stay in the same direction along Gb. In the third iteration, all the duty cycles $d_{1}, d_{2}, d_{3}$ stay at low speed for MPP. At this speed, the duty ratio will be constant, and the system will occupy a stable operating point, which helps in minimizing the oscillations of MPP. If the PV array is in partial shade, the P-V curve faces multi-peak state P1, P2, and P4 local poles while P3 global poles (obtained from $4^{\text {th }}$ iteration as shown in Figure $2(\mathrm{~d})$. The output of the system with duty cycles $d_{1}, d_{2}, d_{3}$ where $\mathrm{Pb}$ is particles, the global peak (P3) is obtained and optimization is initialized at initial duty ratio $\left(\mathrm{P}_{\mathrm{b}}, \mathrm{i}\right)$.

c. Research problem

The work of Yoganandini and Anita [24] have provided an insight into MPPT techniques in PV modules by dealing with existing researches, research gap, and offered a futuristic idea for the research community. From the recent research survey, it is observed that at the slow change in optimal radiations, 
the PSO need to provide an appropriate value of duty cycle. During MPP tracking, changes in air ratio, initialization, and variation in duty ratio, range of the particles in PV-curve increases. Hence, large fluctuations may appear in providing optimal search solution. This yields high computational cost and energy wastage. Another problem which needs to be considered is that tracking of MPP must be fast enough to track speed but, the duty ratio and volatility are not feasible in the PSO algorithm, and it does not yield proper tracking of MPP. Also, change in the intensity of solar radiation, and it leads to variation in operating point. In this scenario, small changes in duty cycle may lead to slower search in MPP. This is more critical during shadow condition. Hence, the empty ratio is not used to search the PV curve in a large area where the traced MPP may be local peak than the global peak. Thus, there is a need for the modified algorithm to overcome the above-stated problem.Hence, the problem statement is "to introduce a modified PSO algorithm to enhance the performance of MPPT from PV array."

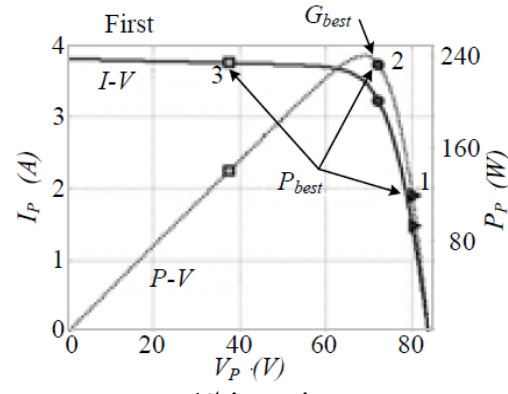

$1^{\text {st }}$ iteration

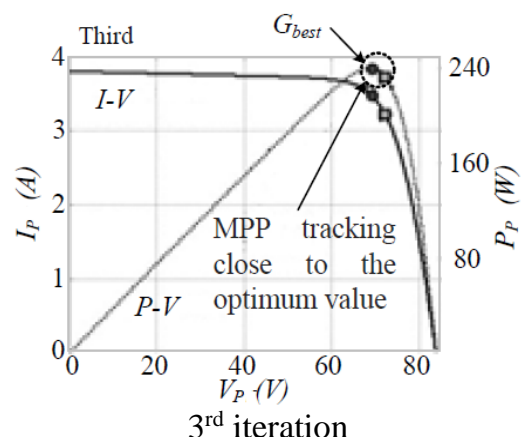

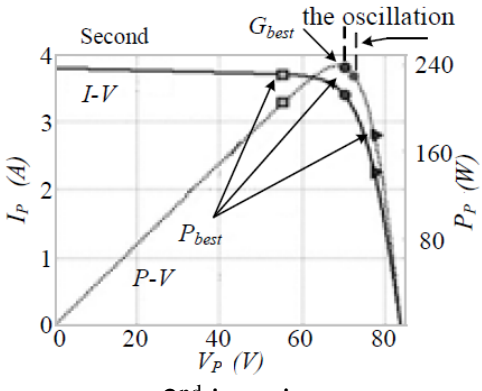

$2^{\text {nd }}$ iteration

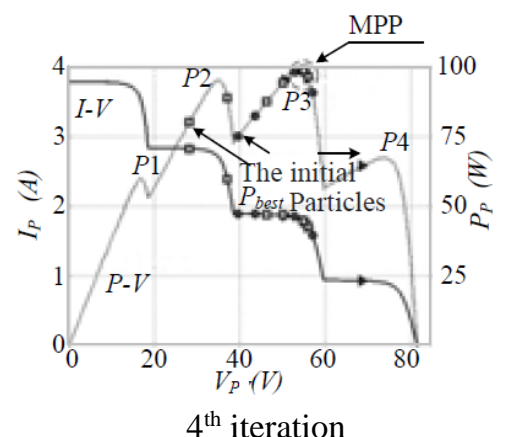

$4^{\text {th }}$ iteration

Figure 2. Movement of particles in different iterations

\section{MODIFIED PSO ALGORITHM FOR MPPT}

The previous work of Yoganandini and Anita [25] have presented a cost-effective MPPT technique for MPPT, where computational time is reduced and achieved cost optimization. This manuscript aims to enhance the performance of the MPP by introducing the modified PSO for the PV array. In the proposed algorithm, the duty cycle is partitioned into two parts. The previous duty ratio exhibits the factor of linearization $\left(\mathrm{K}_{1}\right)$ increases or decreases the ratio based on PV array output. Similarly, in providing new PV curve for MPP by using search optimization, two duty cycles d1 and $\mathrm{d} 3$ in the positive and negative direction to $\mathrm{K}_{2}$ constant value perturbation. The following Figure 3 provides an estimation model for $\mathrm{K}_{1}$ where it can be observed that the maximum power of array and respective power (pMPP), duty ratio, the relationship among $\mathrm{P}_{\mathrm{b}}, \mathrm{G}_{\mathrm{b}}$ to $\mathrm{DC} / \mathrm{DC}$ converter having $\Delta d_{p M P P}$ with respect to duty ratio. The response optimized $\lambda=1$ can be minimized to 0.1 , step 0.1 . However, there exist two expressions are considered, which brings the relationship between dbest and pMPP. Also, there exists a linear relationship between array power and duty.

$$
d_{\text {new }}=d_{\text {old }}-\frac{1}{K_{1}}\left(P_{\text {old }, M P P}-P_{M P P}\right)
$$

$d_{\text {old }}$ is a previous duty ratio for $\mathrm{G}_{\mathrm{b}}$. The slope $\left(K_{1}\right)=\frac{\Delta_{p M M P}}{\Delta d}$ for linear relation changes as per change in 
operating power and its value is almost equal to the new optimal duty cycle. Hence, the initialization of duty ratio must perform the searching of the P-V curve and will quickly do the tracking of new MPP.

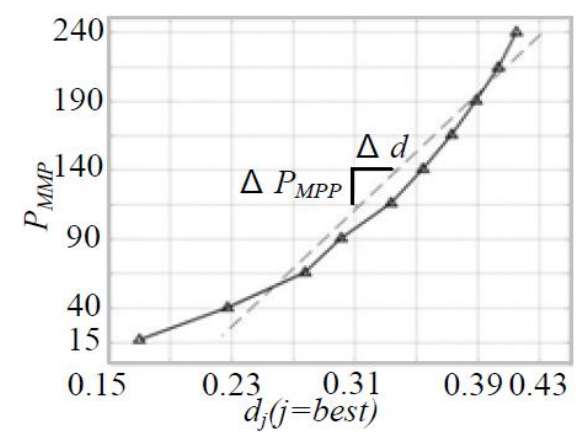

Figure 3. Relation among Gb, duty cycle and pMPP

From the above analysis, it has been found that, the reduction in solar radiation (from wavelength $\lambda=1 \lambda=0.1$ ) always leads to load line in PV array I-V gives maximum MPP voltage (VMPP) to the right of plot curve. The increment in sunshine brings load line to the right. The difference between VMPP and output voltage will become small, and it leads to a small variation in power.Hence, the same value of $d_{\text {old }} \&$ $\mathrm{K}_{1}$ is not to be deleted. Thus, the PSO algorithm needs to have more iteration to track MPP. To neutralize such type of problems, a simple assumption is made with two different values of $\mathrm{K}_{1}$.

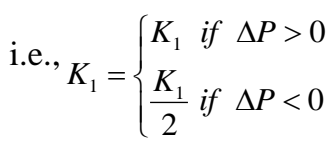

In this equation, $\Delta P=P-P_{\text {old }}$

The value of $\mathrm{P}>0 \& \mathrm{P}<0$ indicates the decrement and increment in sunshine radiation. In order to get the duty ratio of new perturbation for $d_{1}$ and $d_{3}$ respectively. The following formula of data ratio updates position, and negative direction.

$$
\left(d_{i}\right)_{n e w}=\left[\left(d_{1}-K_{2}\right), d_{2},\left(d_{3}+K_{3}\right)\right] \text { Where } K_{2} \geq 0.05
$$

The selection mechanism of this 0.05 helps to manage low power fluctuation but, during the partial shade, the working voltage may increases up to $85 \%$, this helps PSO algorithm to track global peak more. The following section gives the algorithm implementation.

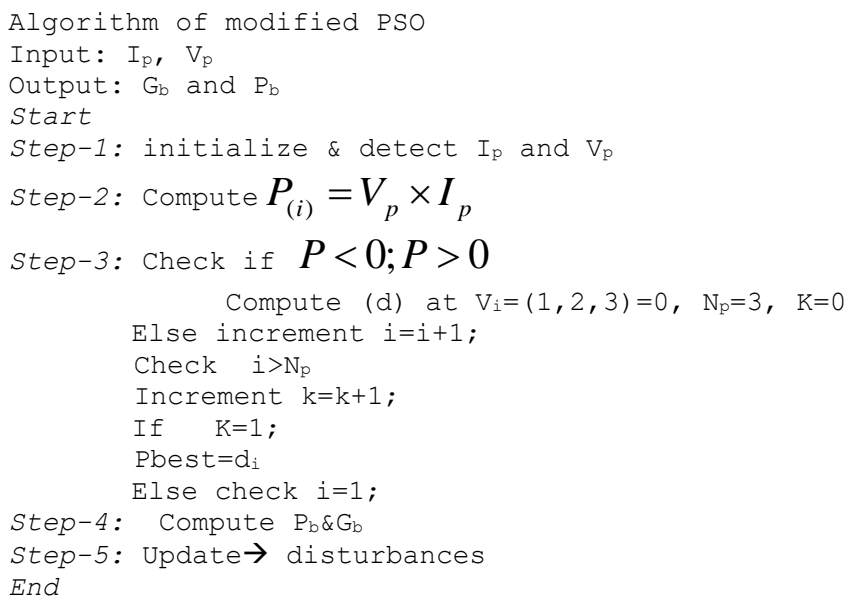


The algorithm is initialized by detecting the PV current (Ip) and PV voltage (Vp) (Step-1). Further, the initial power of the PV cell is computed by using the general formula of power $P_{(i)}=V_{p} \times I_{p}$ (Step-2). Later, the condition of $\mathrm{P}>0$ or $\mathrm{P}<0$ is verified (Step-3). If the condition is satisfied, the duty ratio (d) is calculated at duty cycles $(1,2,3)$ of voltage $\mathrm{Vi}(1,2,2)=0$ number of particles $(\mathrm{Np})=3$, constant $\mathrm{k}=0$. If it is not satisfied, then the number of iterations will be incremented by 1 . Further, it is checked for " $\mathrm{i}>\mathrm{Np}$ " and if it is satisfied, then ' $\mathrm{k}$ ' value is incremented by 1 . If $\mathrm{k}=1$, the " $\mathrm{Pb}$ " value will be duty cycle (di) i.e., $\mathrm{Pb}=\mathrm{di}$. Similarly, if ' $\mathrm{k}=1$ ' is not satisfied, it will be checked for $\mathrm{i}=1$. Then, the value of $\mathrm{Pb}$ can be computed after varying the condition $\mathrm{P}(\mathrm{i})>\mathrm{P}(\mathrm{i}-1)$. In case, the condition is satisfied, then " $\mathrm{Pb}=\mathrm{di}$ " else " $\mathrm{Pb}=\mathrm{d}(\mathrm{i}-1)$. ". Similarly, to calculate global best $(\mathrm{Gb})$ same procedure of incrementing $(i=i+1)$ and checking " $i>N p . "$ Based on this condition, $\mathrm{Gb}$ is computed as,

$$
G_{b}=\max \left(P_{b}\right)
$$

Finally, the disturbance among $\mathrm{Pb}$, output voltage, and $\mathrm{Gb}$ is updated. The duty cycle of disturbance is computed by using previous duty ratio $\mathrm{di}(\mathrm{k})$ and local $\mathrm{Pb}$. The difference between ' $\mathrm{i}$ ' and previous $\operatorname{di}(\mathrm{k})$ and $\mathrm{Gb}$. Hence, the power converter and tracking best $\mathrm{Pb}, \mathrm{Gb}$ and I are possible in the proposed algorithm.

The significance of proposed PSO is that it yields faster search and tracks the MPP optimal solution. After acquiring the MPP by particles, the velocity almost becomes zero. Hence, no oscillations will be observed in steady state. The steady state oscillation is necessary as it is helpful in getting the efficiency of MPPT. Another significant feature of modified PSO is that it exhibits 3-duty cycles, and hence, it does not lose direction in short term fluctuations. The proposed PSO effectively able to track the global peak.

\section{RESULT ANALYSIS}

The proposed system model is simulated using MATLAB. In the optimization process, the fitness value is updated by PV array output power. The performance analysis of the modified PSO is done with traditional PSO under partial shading condition aiming with accurate MPP tracking. Figure 4 represents the tracking result of traditional PSO, where it is observed that a large range of fluctuations exists in optimization. This misjudges the MPP and takes $\sim 0.045 \mathrm{sec}$ for tracking the MPP.

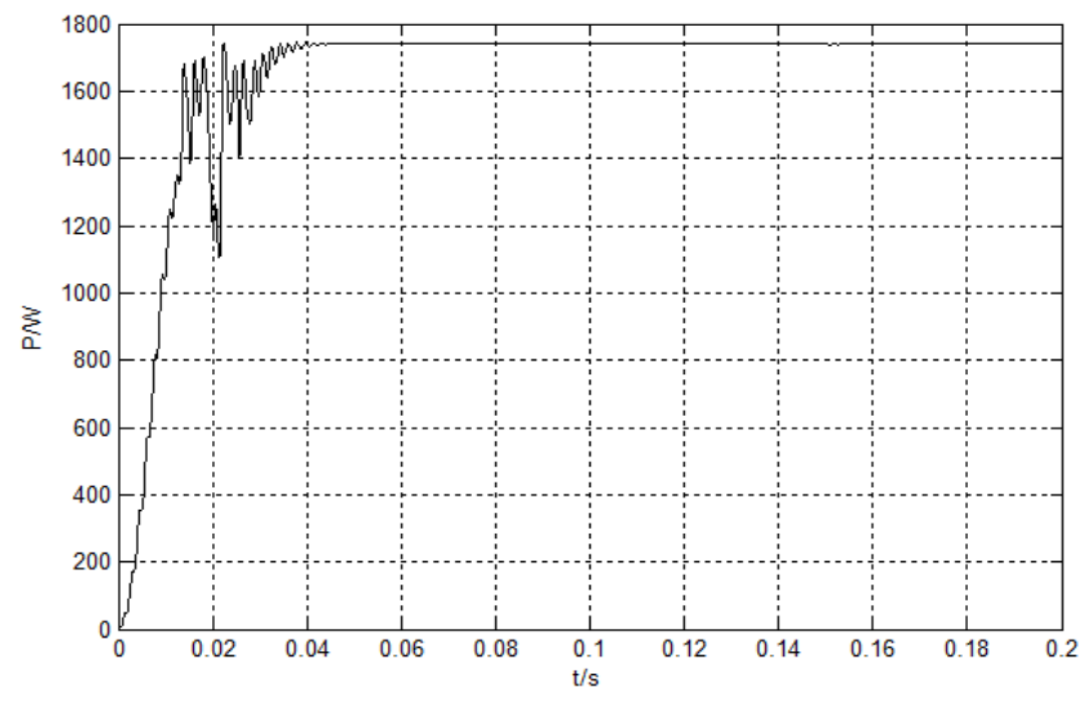

Figure 4. Tracking of MPP with traditional PSO

The proposed, modified PSO considered search-based optimization uses 3-duty cycles and does not lose its direction in short term fluctuation. Figure 5 shows the power Vs. time curve obtained from proposed PSO is smoother than traditional PSO, and it takes only $\sim 0.038 \mathrm{sec}$ for MPP tracking, which is improved about 0.08 secs. Hence, the modified PSO makes the process more stable and improves the MPP performance. The proposed PSO improved the dynamic response speed tracking accuracy in a steady state. 


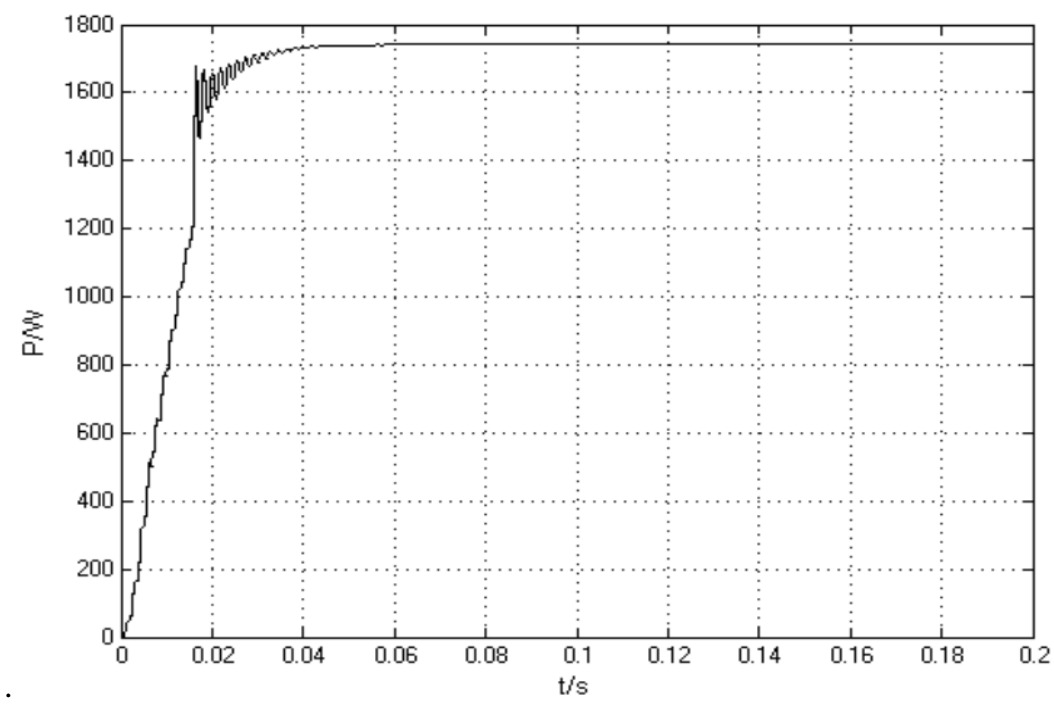

Figure 5. Tracking of MPP with proposed PSO

\section{CONCLUSION}

In this research, the proposed MPP tracking system is aimed to enhance the tracking accuracy and speed. The proposed system introduced an MPPT technique based on the modified PSO algorithms which bring high efficiency. The search based method is considered with 3-duty cycles and does not lose its direction in short term fluctuation in steady state. Another significance is that the proposed PSO has taken less time $(0.038 \mathrm{secs})$ to track the MPP than traditional MPP $(0.045 \mathrm{sec})$ found improvement of $0.008 \mathrm{secs}$. This gives that the performance of the MPPT is enhanced with an efficiency of $99 \%$. The scope of the proposed study is that it can be considered with other machine learning approaches under different environmental condition. Further, the research can be carried out with different types of PV arrays.

\section{REFERENCES}

[1] Ellabban, Omar, Haitham Abu-Rub, and Frede Blaabjerg, "Renewable energy resources: Current status, future prospects and their enabling technology," Renewable and Sustainable Energy Reviews, vol. 39, pp. 748-764, 2014.

[2] Devabhaktuni, Vijay, et al., "Solar energy: Trends and enabling technologies," Renewable and Sustainable Energy Reviews, vol. 19, pp. 555-564, 2013.

[3] E. Koutroulis, K. Kalaitzakis and N. C. Voulgaris, "Development of a microcontroller-based, photovoltaic maximum power point tracking control system," Power Electronics, IEEE Transactions on, vol. 16, no. 1, pp. 46-54, 2001.

[4] Ishaque, Kashif, and Zainal Salam, "A review of maximum power point tracking techniques of PV system for uniform insolation and partial shading condition," Renewable and Sustainable Energy Reviews, vol. 19, pp. 475-488, 2013.

[5] Singh, Girish Kumar, "Solar power generation by PV (photovoltaic) technology: A review," Energy, vol. 53, pp. 1-13, 2013.

[6] A. N. A. Ali, et al., "A survey of maximum PPT techniques of PV systems," in Energytech, IEEE, pp. 1-17, 2012.

[7] Y H Yang, and K L Zhou, "Photovoltaic Cell Modeling and MPPT Control Strategies," Transactions of China Electrotechnical Society, vol. 26, pp. 229-234, 2011.

[8] Parlak K S, and Can H. "A new MPPT method for PV array system under partially shaded conditions," IEEE International Symposium on Power Electronics for Distributed Generation Systems (PEDG), pp. 437-441, 2012.

[9] X Zhang, and R X Cao, "Solar Photovoltaic (PV) Grid Generation and Its Inverter Control", Mechanical Industry Press, 2011.

[10] Ramaprabha R, et al., "Modified Fibonacci search based MPPT scheme for SPVA under partially shaded conditions," 3rd International Conference on Emerging Trends in Engineering and Technology, IEEE, pp. 379-384, 2010.

[11] Y Shi, et al.," Optimized Operation of Current-Fed Dual Active Bridge DC-DC Converter for PV Applications," IEEE Transactions Industrial Electronics, vol. 62, no. 11, pp. 6986-6995, 2015.

[12] I. A. Gowaid, et al., "Analysis and Design of a Modular Multilevel Converter with Trapezoidal Modulation for Medium and High Voltage DC-DC Transformers," IEEE Transactions Power Electronics, vol. 30, no. 10, pp. 5439-5457, 2014.

[13] P. C. Cheng, et al., "Optimization of a Fuzzy-Logic-Control-Based MPPT Algorithm Using the Particle Swarm Optimization Technique,” Energies, vol 8, issue 6, pp. 5338-5360, 2015. 
[14] P. Singh, et al., "Comparison of Photovoltaic Array Maximum Power Point Tracking Techniques," International Advanced Research Journal in Science, Engineering and Technology, vol. 2, no. 1, pp. 401-404, 2015.

[15] M. Yaichi, M. K.Fellah, and A. Mammeri, "A Neural Network Based MPPT Technique Controller for Photovoltaic Pumping System," International Journal of Power Electronics and Drive Systems, vol 4, no. 2, pp. 241-255, 2014.

[16] Hamlili, Boubakeur, Khelifa Benahmed, and Brahim Gasbaoui, "Behaviour of solar wireless sensor network in saharan region under different scenarios consideration," International Journal of Electrical and Computer Engineering (IJECE), vol. 10, no. 3, pp. 2797-2806, 2020.

[17] Ba-razzouk, A., et al., "Backstepping based power control of a three-phase single-stage grid-connected PV system," International Journal of Electrical and Computer Engineering (IJECE), vol. 9, no. 6, pp. 4738-4748, 2019.

[18] Samosir, Ahmad Saudi, and Herri Gusmedi, "Modeling and simulation of fuzzy logic based maximum power point tracking (MPPT) for PV application," International Journal of Electrical and Computer Engineering (IJECE), vol. 8, no. 3, pp. 1315-1323, 2017.

[19] K., Ishaque, and Z., Salam, "An improved modeling method to determine the model parameters of photovoltaic (PV) modules using differential evolution (DE)," Solar Energy, no. 85, no. 9, pp. 2349-2359, 2011.

[20] K.Ishaque, Z.Salam, and H.Taheri "Simple, fast and accurate two diode model for photovoltaic modules," Solar Energy Mater Solar Cells, vol. 95, no. 2, pp. 586-594, 2011.

[21] Jiao Yang, Song Qiang, and Liu WenhuaL, "Practical simulation model of photovoltaic cells in photovoltaic generation system and simulation," Power System Technology, (in Chinese), vol. 34, no. 11, pp. 198-202, 2010.

[22] Li Chunhua, Zhu Xinjian, "Modeling and performance analysis of photovoltaic/fuel cell hybrid power generation systems," Power System Technology, (in Chinese), vol. 33, no. 12, pp. 88-92, 2009.

[23] Liu Dongran, et al., "A review on models for photovoltaic generation system," Power System Technology, (in Chinese), vol. 35, no. 8, pp. 47-52, 2011.

[24] Yoganandini, A. P., and G. S. Anitha. "Insights of the Advancement in Maximum Power Point Tracking Techniques in PV Module," Communications, vol. 4, no. 3, pp. 15-25, 2016.

[25] Yoganandini, A. P., and G. S. Anitha. "A cost effective computational design of maximum power point tracking for the photo-voltaic cell," International Journal of Electrical and Computer Engineering (IJECE), vol. 9, no.2, pp. 851-860, 2019.

\section{BIOGRAPHIES OF AUTHORS}
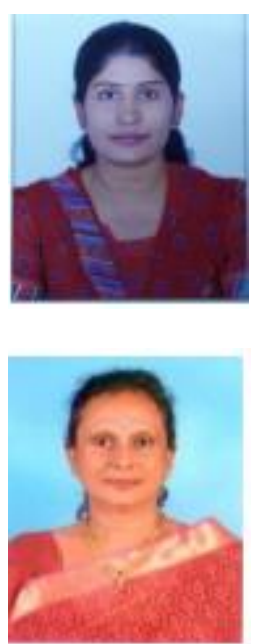

Yoganandini A. P., she has studied BE in Electrical \& Electronics Engineering from STJIT, Karnataka university, Dharwad. M.Tech in computer applications in industrial drives from M. S. Ramaiah Institute of Technology, Bangalore from Visveswaraiah Technological university, Belgaum, Karnataka, India. Pursing PhD in area of Photovoltaic module. Published eight papers in International journals. Five papers in national conferences Attended international conference conducted at Dubai, UAE, got best paper award in year 2015 March. Currently working as an Assistant Professor in Sambharam Institute of Technology, Bangalore, Karnataka, India. Having 12 years of teaching experience.

Dr. Anitha., she has studied BE in electrical \& Electrical engineering and M.Tech in power system Engineering from UVCE, Karnataka, India, PhD in Renewable energy source from Avinasamlingum University, koyamattur, Tamilnau, India Published Fifteen international Journals and Ten national journals and Attended Ten international conference. Having 34 years of teaching experience, currently working as an Associate Professor in Electrical and Electronics Department R.V college of Engineering, Bangalore, Karnataka, India. 